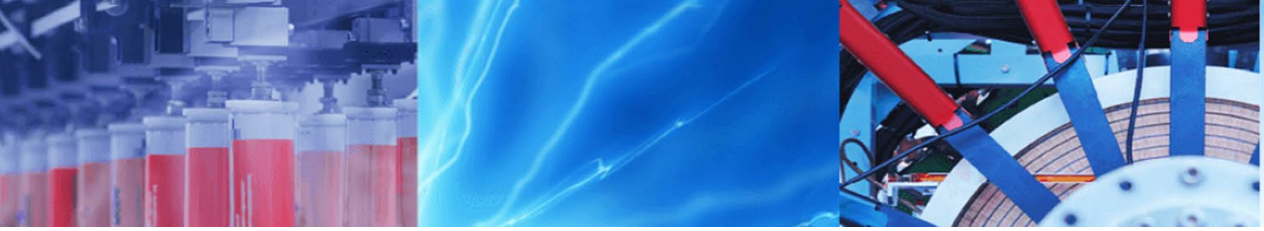

Research Article

\title{
Tidal and non-tidal components of water level and currents in the Sundarbans ecosystem
}

\author{
J. Selvin Pitchaikani ${ }^{1,3}$. Prasad K. Bhaskaran ${ }^{2}$
}

(c) Springer Nature Switzerland AG 2019

\begin{abstract}
The present study is an effort to understand the complex tidal characteristics and flow conditions at Kaikhali station located in the Matla River of the Indian Sundarbans ecosystem. The study region is located south of the low-lying Ganges-Brahmaputra deltaic environment that is highly vulnerable to the impact of sea level rise. The maximum recorded tidal range at Kaikhali location is about $6.35 \mathrm{~m}$, and the current speed varied between 0.03 to $1.18 \mathrm{~m} \mathrm{~s}^{-1}$ with an average speed of $0.48 \mathrm{~m} \mathrm{~s}^{-1}$ during the observation period. The currents closely followed the flood and ebb phases of the tidal cycle with a maxima recorded during the spring high tide conditions. The predominant current direction was northeast (NE) and southwest (SW) during the flood and ebb phases of the tidal cycle, respectively. The tidal characteristics are semidiurnal in nature, and among the five major tidal constituents $\mathrm{M}_{2}, \mathrm{~S}_{2}, \mathrm{~K}_{1}, \mathrm{O}_{1}$ and $\mathrm{N}_{2}$, the relative influence of principal lunar $\left(\mathrm{M}_{2}\right)$ and principal solar $\left(\mathrm{S}_{2}\right)$ components contributes $58 \%$ and $25 \%$, respectively. The circulation characteristic in this ecosystem is a result of the combined effects of freshwater discharge from riverine tributaries, creeks and tidal propagation from the open sea. A detailed investigation performed in the present study using the measured data signify that the tidal currents dominate as compared to the non-tidal components in this region. The study has practical applications in understanding the estuarine hydrodynamics over this region.
\end{abstract}

Keywords Sundarbans · Matla River · Tide · Kaikhali · Current

\section{Introduction}

The Sundarbans region located in the head Bay of Bengal region is the largest deltaic tidal halophytic mangrove forest in the world [1], situated at the confluence of two major Himalayan rivers Ganges and Brahmaputra and periodically exposed to heavy monsoon rains, strong tidal currents, cyclonic wind gusts, floods and storms surges $[2,3]$. This ecosystem is influenced by different environmental drivers that vary over monthly and seasonal scales. Various responsible physical factors such as the tidal pattern, water discharge from creeks, intensity and strength of tidal currents, sediment heterogeneity, reversing wind system and wave action contributes to the overall complexity of this coastal environment $[4,5]$. The ecosystem spreads over an area of approximately $19,509 \mathrm{~km}^{2}$, and UNESCO considered this deltaic environment as a world heritage site owing to its fertile, low-lying alluvial plains [6]. Tidal information along the coastal areas is very important in order to estimate the tide-induced currents, coastal zone management and for shoreline management plans. Tides in coastal waters are periodic in nature and expressed as the sum of a large number of tidal harmonic constituents. High tidal range and strong currents prevalent over this region play an important role in controlling the suspended sediment concentration and sediment transport

$\triangle$ J. Selvin Pitchaikani, selvinocean@gmail.com | ${ }^{1}$ ICZM Project, State Project Management Unit, Institute of Environmental Studies \& Wetland Management, DD-24, Sector-I, Salt Lake City, Kolkata, West Bengal 700 064, India. ${ }^{2}$ Department of Ocean Engineering \& Naval Architecture, Indian Institute of Technology Kharagpur, Kharagpur, West Bengal 721 302, India. ${ }^{3}$ Present Address: National Centre for Sustainable Coastal Management, Ministry of Environment, Forest and Climate Change (MoEF\&CC), Anna University Campus, Chennai 600025, India. 
mechanisms thereby playing an active role in shaping the ecosystem geomorphology. Water level elevations for this region experiences the highest tidal range reported for the East coast of India [6]. The tidal propagation in the Sundarbans region is quite complex, owing to the presence of numerous creeks, shallow bathymetry, mudflats, earthen embankments and mangrove ecosystems. Tides and associated tidal currents form the major source of energy for turbulence and mixing in estuaries play an important role in the transport of dissolved and particulate matter, creating oscillatory fluxes in the physical and chemical properties [5]. Apart from the tidal currents caused by the lunar and solar tractive forces, there are also non-tidal currents that arise from other sources [7] having an important role in the ecosystem dynamics. The residual circulation in estuaries caused by the density difference between fresh and ocean water consists of the surface layers flowing seaward and the bottom layers flowing landward [8]. The constant mixing between freshwater and seawater can result in the formation of stratified/de-stratified layers of water masses in an ecosystem environment. Besides the observed attributes of tides in this ecosystem, the subsurface action is constantly present in the form of tidal circulation [7]. The saline water environment in the Sundarbans region is measurably diluted by freshwater discharged from the Hooghly River, creeks and the sub-tidal flow. Bhattacharyya et al. [9] reported that the tidal range at Gosaba (one part of the Sundarbans estuary) is about $6 \mathrm{~m}$, and Mishra et al. [10] reported that the magnitude of simulated tide-induced currents increased along the east coast of India, and the general current direction is northward toward the head Bay. In order to mitigate seawater intrusion, and to protect paddy field from natural hazards such as tropical cyclones-induced storm surge and flooding, sea level rise, etc., the inhabitants of the Sundarbans region have constructed embankments [11]. These clay embankments have prevented siltation on the former intertidal surface such that their elevation falls relative to the rising sea levels $[9,12]$. Relative sea level in the Sundarbans region are rising, due to eustatic processes, land subsidence resulting from auto-compaction, tectonic activity and anthropogenic processes including water abstraction from tube wells [9]. Predicted eustatic sea level rise due to accelerated global warming extends over a range between 0.5 and $2.0 \mathrm{~m}$ by the year 2100 [13, 14]. At present, the clay embankments are facing severe erosional problem due to tidal action, rising water levels, storm surge induced overtopping and breaches in embankments having implications to widespread flooding. This type of low-level flooding has been termed as nuisance flooding (NF) in a coastal context [15] and minor flooding (MF) in a fluvial context [16]. Compared to extreme flooding and disasters, the occurrence and impacts of nuisance flooding (NF) are poorly understood in Indian coastal waters. Systematic monitoring across coastal and inland sites is a starting point for advancing knowledge about NF and MF, and in turn, developing policy responses and management measures [17]. The Ganges-Brahmaputra-Meghna delta is constantly changing as a result of variations in flows and sediment loads [9]. Similarly, the flow patterns and erosions are also changing and expected to be changed, as a result of nuisance flooding. The Sundarbans region has lost about $100 \mathrm{~km}^{2}$ in the past 30 years, with effects of erosion felt mainly on the southern shores of islands [17]. In 2015, erosion rates in the Indian Sundarbans region were reported to be higher than accretion [18]. Further studies on flood impacts and return period of extreme events, etc., are important for preparing the management policies for shoreline and disaster control and preparedness in this region.

Several studies related to tidal dynamics have been conducted for the west coast of India; however, studies on tidal pattern and dynamics for the east coast bordering the Bay of Bengal (BoB) are very limited. Murty and Henry [19] developed co-tidal charts for major tidal constituents using a numerical model for the east coast of India. Sindhu and Unnikrishnan [20] developed a vertically integrated two-dimensional numerical model to simulate major tidal constituents $\left(\mathrm{M}_{2}, \mathrm{~S}_{2}, \mathrm{~N}_{2}, \mathrm{~K}_{1}\right.$ and $\left.\mathrm{O}_{1}\right)$ for the BoB region. Linta and Bhaskaran [21] studied the nonlinear tidal characteristics for the head Bay of Bengal region. Maximum tidal amplification occurs at the head Bay, along a zone enclosing the mouth of the tidal inlets. Linta and Bhaskaran [21] developed a model that predicts and provides a comprehensive evaluation on the combined effect of astronomical, meteorological and hydrological forcing on the net water elevation over this region. Linta et al. [6] developed a tide prediction system for the Gangra location located in the Hooghly estuary. Mishra et al. [10] reported on the nature of tide-induced flow field along the east coast of India. Chatterjee et al. [22] provided a comprehensive overview on the observed variations in water level influenced by tides at 30 locations in the Indian Sundarbans region. Except this study, no other studies were conducted for the Sundarbans region. The Indian part of Sundarbans region is data void, and there exist no water level observation system in the deltaic environment. Tide-dominated ecosystem and deltaic deposits accumulated in the fluvialto-marine transition zone varies and is considered as one of the most complicated as compared elsewhere, due to the mutual interaction between large number of terrestrial and marine processes. Various studies were carried out in this fertile environment pertaining to chemical and biological characteristics of the coastal ecosystem. However, the physical oceanographic characteristics of this region was relatively less understood and hence the measured 
data used in this study is one step forward to understand the tidal characteristics and flow patterns in the estuary linked to the morphology of this region.

\section{Data and methodology}

The Hooghly Estuary forms the lower part of the River Ganges, and apart from the Hooghly and Matla rivers, there are many other riverine systems that crisscross the Indian part of the Sundarbans region namely Bidya, Saptamukhi, Raimangal, Muriganga, Thakuran and Gomor. The Indian part of Sundarbans region lies between the geographical coordinates bounded between $21^{\circ} 30^{\prime}$ to $22^{\circ} 15^{\prime} \mathrm{N}$ and $88^{\circ}$ to $89^{\circ} \mathrm{E}$ (Fig. 1). A total of nine rivers (Saptamukhi, Thakuran, Matla, Bidya, Gomdi, Gosaba, Gona, Harinbhanga and Raimangal) flowing from north to south [15] discharge into the deltaic environment in this region. The present study conducted field-based measurements in the Matla River at Kaikhali location (latitude: $22^{\circ}$ $02^{\prime} 42.60^{\prime \prime} \mathrm{N}$; longitude: $88^{\circ} 38^{\prime} 27.57^{\prime \prime}$ E) at a water depth of $10 \mathrm{~m}$ (Fig. 1). The field data were collected during the pre-monsoon season from March 15, 2011, until April 14, 2011, at 10-min interval. The water level measurement for this region was conducted using a Valeport Wave and Tide Recorder (WTR). The current speed and direction were measured using the Aanderaa SeaGuard (RCM) current meter. Further, the tidal and non-tidal components were segregated as both $U$ and $V$ components of currents and water level using MIKE 21 [23], and the respective tidal constituents were estimated.

\section{Results and discussions}

The tide and current data were collected and analyzed for the Kaikhali station in Matla River, an upstream location in the Sundarbans region. Maximum observed tidal range was $6.35 \mathrm{~m}$ with a form number less than 0.06 and is semidiurnal in nature. The flow characteristic in this region is primarily controlled by the tidal propagation with tidal range varying between 0.16 and $6.51 \mathrm{~m}$. In general, the tidal range increases from mouth to head for all estuaries due to the convergent channel geometry
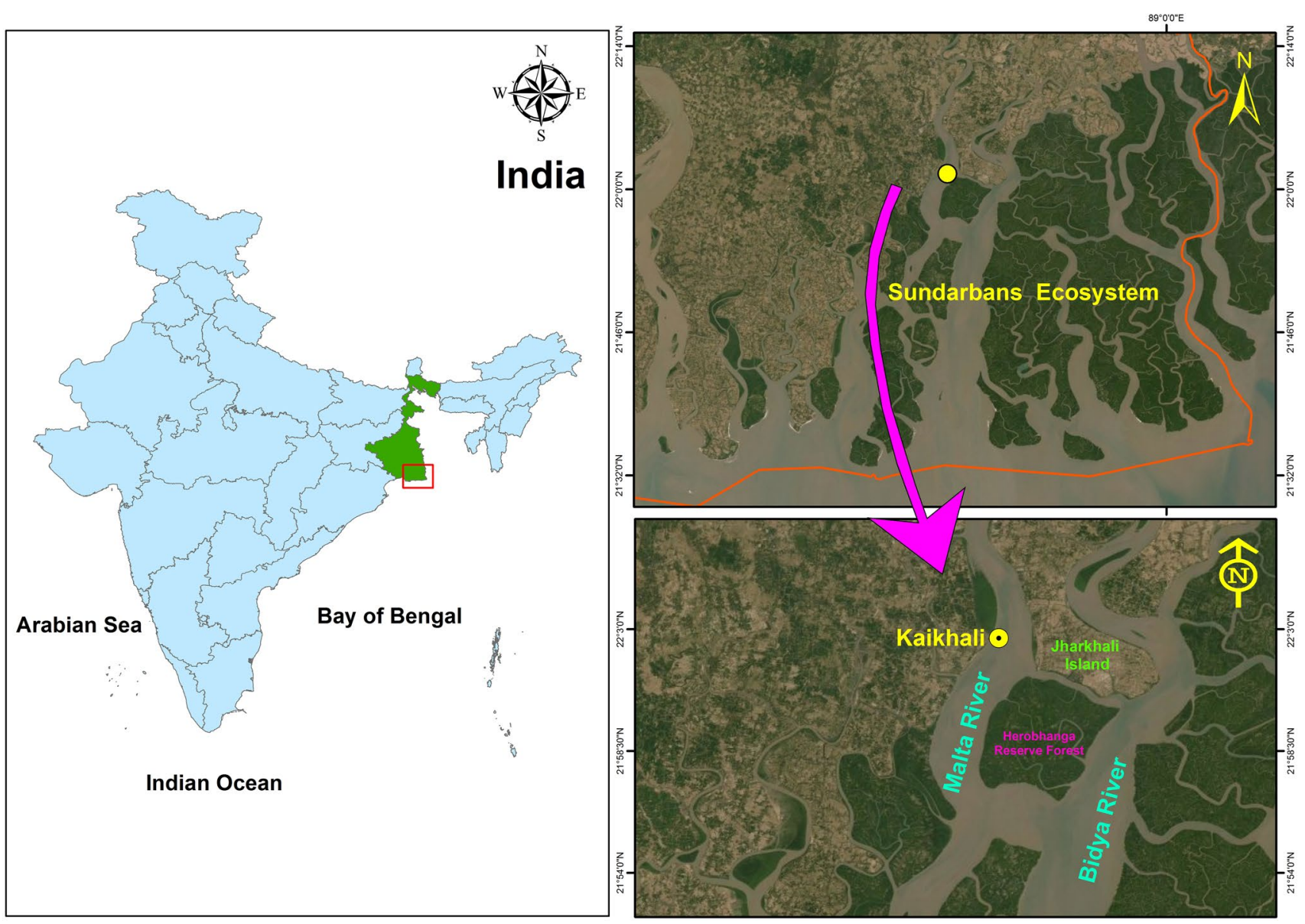

Fig. 1 Map of the study area with enlarged view of Kaikhali location in the Sundarbans ecosystem 
(funnel-shaped) and varying frictional effects governing the rates of amplification at various stretches as a result of flood-dominant and ebb-dominant tidal asymmetries [15]. At Kaikhali station, the observed mean water level was about $3.8 \mathrm{~m}$. Tidal dynamics in the Sundarbans region is also influenced by the coastline geometry, bottom topography, meteorological factors and river discharge from the Hooghly River [15]. Changes in bathymetry and topographical induced variations in turn govern the overall pattern and propagation of tides into shallow continental shelves and further into nearshore and riverine environments [21]. Tidal dynamics is also influenced by barotropic flows, which is ultimately governed by the atmospheric pressure. According to Milliman [24], the eastern part of the Sundarbans delta experiences a higher rate of subsidence due to sediment loading. This subsidence rate is often close to $6 \mathrm{~mm}$ /year as measured at some places of Bangladesh [25]. The changes in bottom topography due to subsidence effect can also change the tidal flow in the study area. The funnelshaped characteristics of the head Bay region along with high tidal range, presence of numerous riverine discharge systems, low-lying topography and shallow bathymetry off the region amplifies the risk due to storm surge and inundation [6]. Figures 2 and 3 illustrate the measured current speed and direction and wind speed and direction of the study area. The observed current speed varied between 0.03 and $1.2 \mathrm{~m} \mathrm{~s}^{-1}$ with an average speed of $0.48 \mathrm{~m} \mathrm{~s}^{-1}$. The maximum current speed $\left(1.2 \mathrm{~m} \mathrm{~s}^{-1}\right)$ and spring tide were observed during March 23, 2011 (Fig. 4), due to collective influence of gravitational forces of both the Moon and Sun on the Earth. The

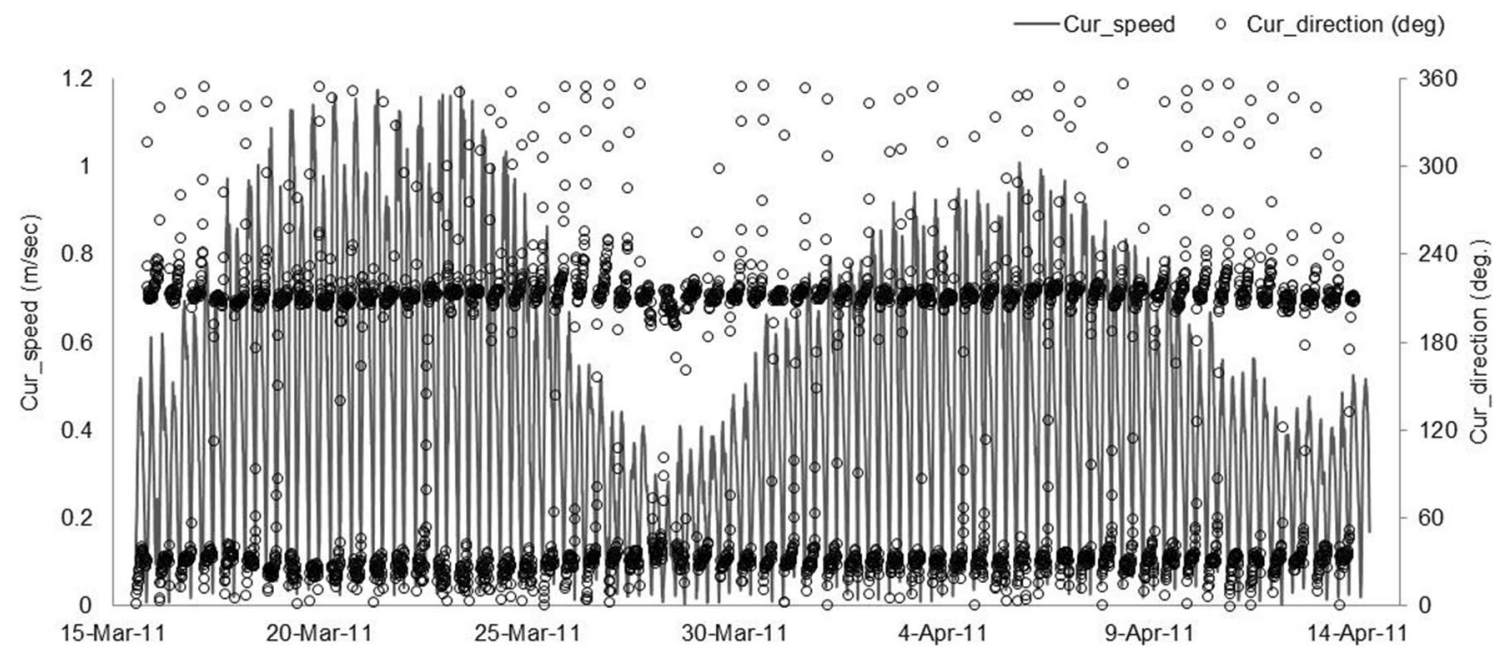

Fig. 2 Observed current speed (in $\mathrm{m} / \mathrm{s}$ ) and direction (in degrees) at Kaikhali location

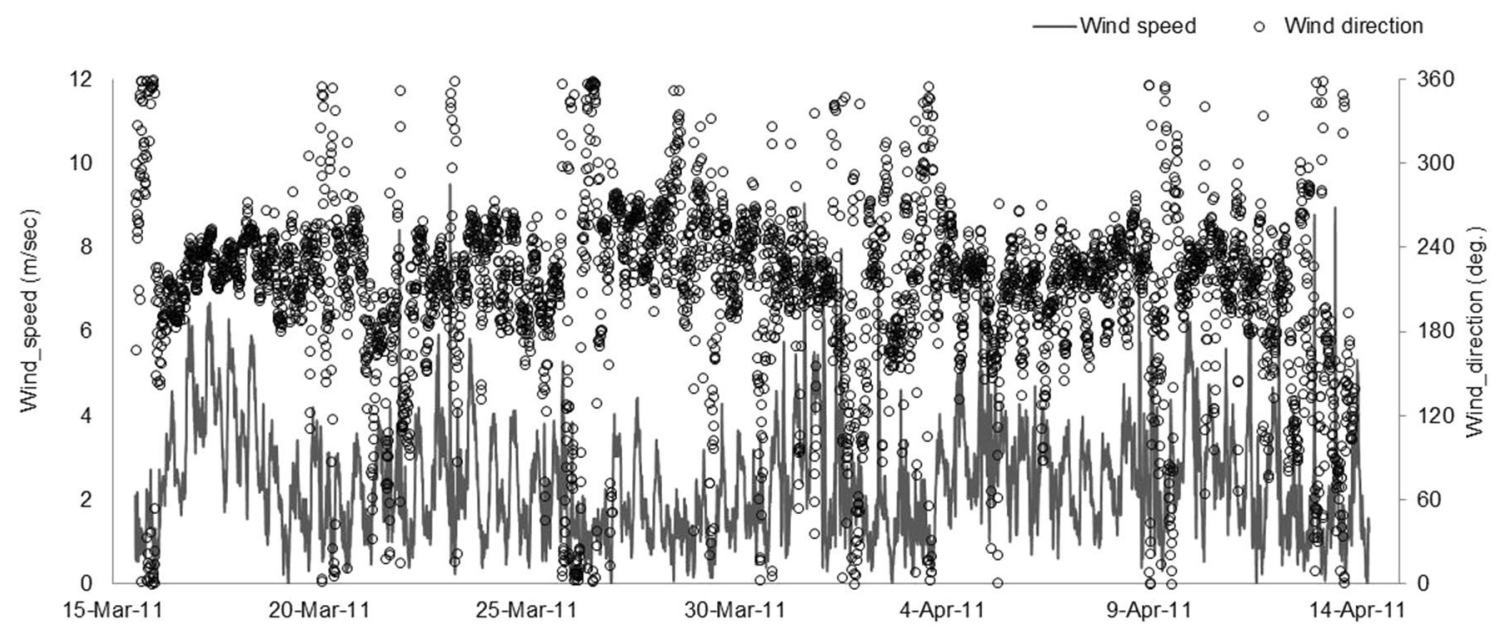

Fig. 3 Observed wind speed (in $\mathrm{m} / \mathrm{s}$ ) and direction (in degrees) at Kaikhali location 

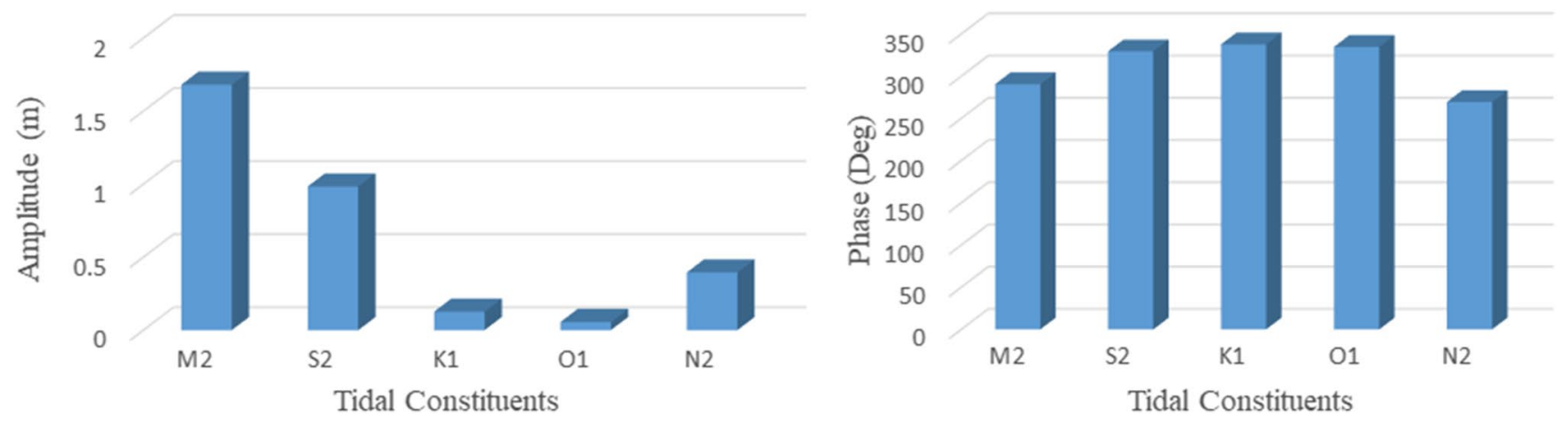

Fig. 4 Amplitude (in meters) and phase (in degrees) of various tidal constituents at Kaikhali location
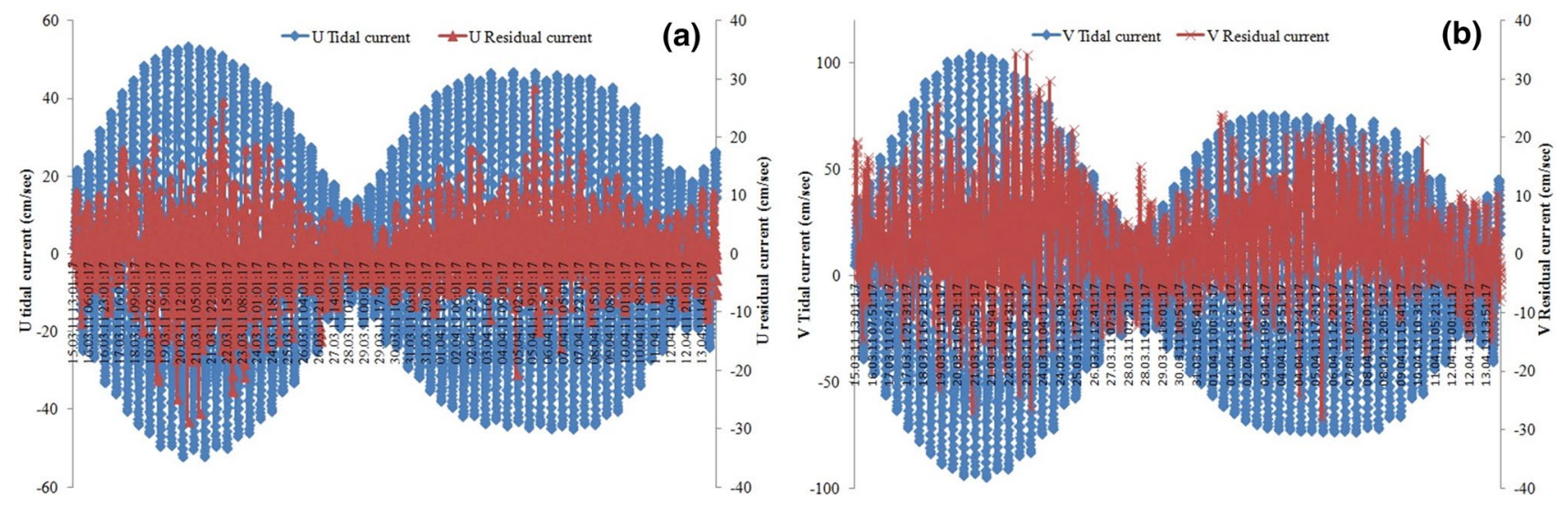

Fig. 5 Zonal and meridional components of tidal and the residual currents (in $\mathrm{cm} / \mathrm{s}$ ) modeled using MIKE21

largest annual tidal range is expected around the time of equinoxes, if it coincides with the spring tide [26]. An equinox is commonly regarded as the instant of time when the plane of Earth's equator passes through the center of the Sun. This occurs twice each year around 20 March and 23 September. In the present study, the data were collected during the month of March and that results in observed high current speed during the study period. In general, the tidal currents are assumed to vary with height above the bottom boundary due to eddy viscosity. The eddy viscosity is a time-independent composite of contributions from major tidal constituents, similar to the study by Smith and Long [27]. One advantage of this approach is that each tidal constituent is governed by a set of linear equations. The currents are described in terms of their east ( $u$-component) and north ( $v$-component) and the estimated $u$ and $v$ components along with the residual currents are shown in Figs. 5, 6. Tidal currents dominate as compared to the non-tidal currents in the Matla River of the Sundarbans region. Daily variations in varying water levels attributed due to tidal influence significantly affect this dynamic environment. In addition, the water quality characteristics, in particular

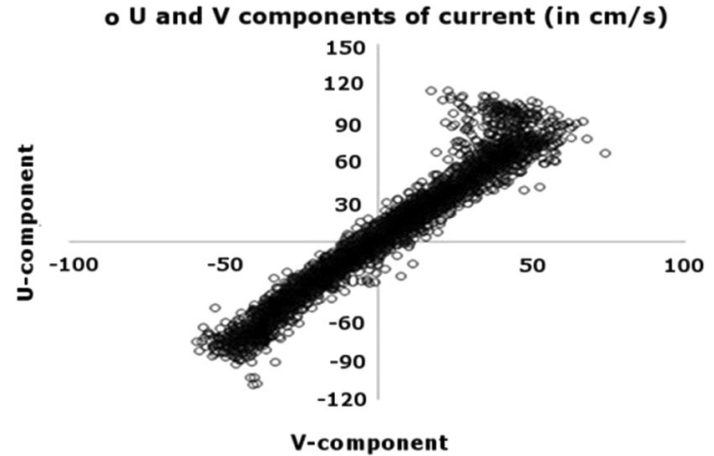

Fig. 6 Measured zonal and meridional components of currents (in $\mathrm{cm} / \mathrm{s}$ )

the nutrients dynamics and dissolved oxygen concentrations in this region, are also significantly influenced by the semidiurnal variation of tides. Water level variation in an estuary depends on its geographical setting, the coastline shape, local water depth and prevailing wind system, and any restrictions to the water flow [12]. Figures 6 and 7 depict the scatter plot and rose diagram pertaining to the $u$ and $v$ components that reveals the 


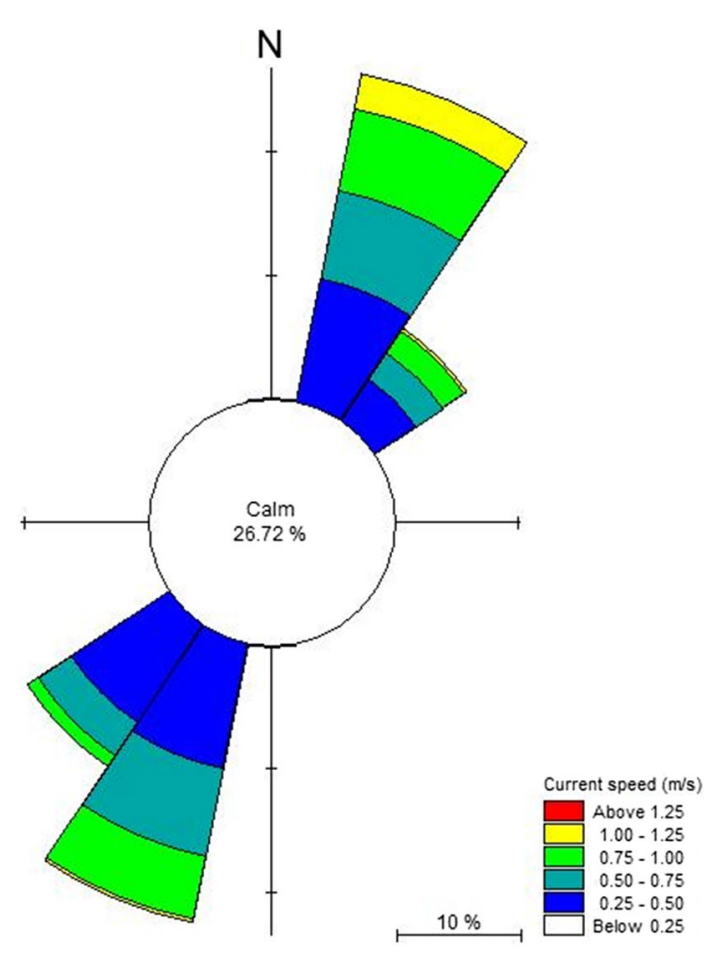

Fig. 7 Rose diagram showing the measured current speed (in $\mathrm{m} / \mathrm{s}$ ) and direction (in degrees) at Kaikhali location

dominance of north-south flow in the Sundarbans region. In particular, the northeast and southwest flows are the dominant modes that correspond to the ebb and flood phases of the tidal system. Figure 4 depicts the tidal analysis of harmonic constituents for the Kaikhali location and five major constituents that dominate the tidal dynamics over this location. The relative influence of five dominant tidal constituents and their respective percentage contributions are shown in Fig. 4. It indicates that the dominant tidal constituents are $\mathrm{M}_{2}, \mathrm{~S}_{2}, \mathrm{~K}_{1}, \mathrm{O}_{1}$ and $\mathrm{N}_{2}$. In the vicinity of the study region, Linta et al. [6] in their recent study corresponding to the Gangra location in the Hooghly estuary performed a detailed location-specific tidal analysis and prediction utilizing one hourly tide data with SLPR2 harmonic tidal analysis tool. Their study reported on the influence of complex bathymetric features on the tidal analysis at Gangra revealing the presence of luni-solar synodic fortnightly tidal constituents (Msf tides) which are noted only at very few locations in India. The tidal analysis also revealed a good match with measured water level data. In the present study, the tidal harmonic constituents generated for the Gangra location were also compared with the present study area. The study by Linta et al. [6] revealed eight significant tidal constituents among the 59 constituents for one full year that dominate the water level elevation at Gangra location in the Hooghly estuary. Also, the Gangra location referred in this study is the nearest location of Matla River in the Sundarbans region. The eight dominant tidal constituents and their respective periods in ascending order at Gangra are as follows: (1) $\mathrm{MS}_{4}$ (shallow water quarter diurnal, $6.10 \mathrm{~h}$ ); (2) $M_{4}$ (shallow water over tides of principal lunar, $6.21 \mathrm{~h}$ ); (3) $\mathrm{S}_{2}$ (principal solar, $12.00 \mathrm{~h}$ ); (4) $\mathrm{M}_{2}$ (principal lunar, $12.42 \mathrm{~h}$ ); (5) $\mathrm{N}_{2}$ (large lunar elliptic, $12.66 \mathrm{~h}$ ); (6) $\mathrm{K}_{1}$ (lunisolar diurnal, $23.93 \mathrm{~h}$ ); (7) $\mathrm{O}_{1}$ (lunar diurnal, $25.81 \mathrm{~h}$ ) and (8) Msf (luni-solar synodic fortnightly, $354.36 \mathrm{~h}$ ) [6]. Comparing of tidal harmonic constituents at Matla River, the area of interest reveals that there are five tidal constituents that are predominant and their respective periods in ascending order are as follows: $M_{2}$ (principal lunar, $12.42 \mathrm{~h}$ ), $\mathrm{S}_{2}$ (principal solar, $12.00 \mathrm{~h}$ ), $\mathrm{K}_{1}$ (luni-solar diurnal, $23.93 \mathrm{~h}$ ), $\mathrm{O}_{1}$ (lunar diurnal, $25.81 \mathrm{~h}$ ) and $\mathrm{N}_{2}$ (large lunar elliptic, $12.66 \mathrm{~h}$ ). It is apparent from this distribution that $M_{2}$ dominates the water level elevation at Kaikhali of Sundarbans ecosystem. In general, the tidal harmonic analysis clearly reveals that the tidal pattern at Kaikhali is of semidiurnal characteristics. Observed and predicted tides showed that both amplitude and phase of the tidal cycle exhibited a good match (Fig. 8). The study therefore reveals that the overall predictive skill of MIKE 21 model is highly satisfactory. The predominant directions of current patterns are observed to be northeast (NE) and southwest (SW) directions, respectively, during the flood and ebb phases. In general, the northward and southward flows are predominant in the Sundarbans ecosystem [15].

The tidal effects at Kaikhali location of the Matla River during the phase of flood tides can accumulate considerable amount of freshwater along with the summer rainfall. The two-way exchange between river and tidal flow plays an important role in the ecosystem. However, the flow regime is controlled by tidal propagation from open sea, as river flow had been disconnected from Hooghly River. The forcing functions controlling the water circulation dynamics in the Sundarbans region are tidal propagation caused by astronomical tide and wind pattern. As the current flow is controlled by tidal forcing, the maximum current speed was observed during the high tide condition. There are two distinct wind flow patterns that persist in Sundarbans during the pre-monsoon season, from March to July, wherein the wind flows from southwest (SW) through south-southwest SSW (in May-June) and gradually the direction changes to south (S) and southeast (SE). Thereafter, the winds are north-northeast (NNE) during October and north-northeast direction persists until January [28]. Also the net transport of water in the Sundarbans ecosystem by ebb and flood tidal currents is influenced by the flow from open sea. The dominant flood current implies strong tidal flow resulting in an inward transport 


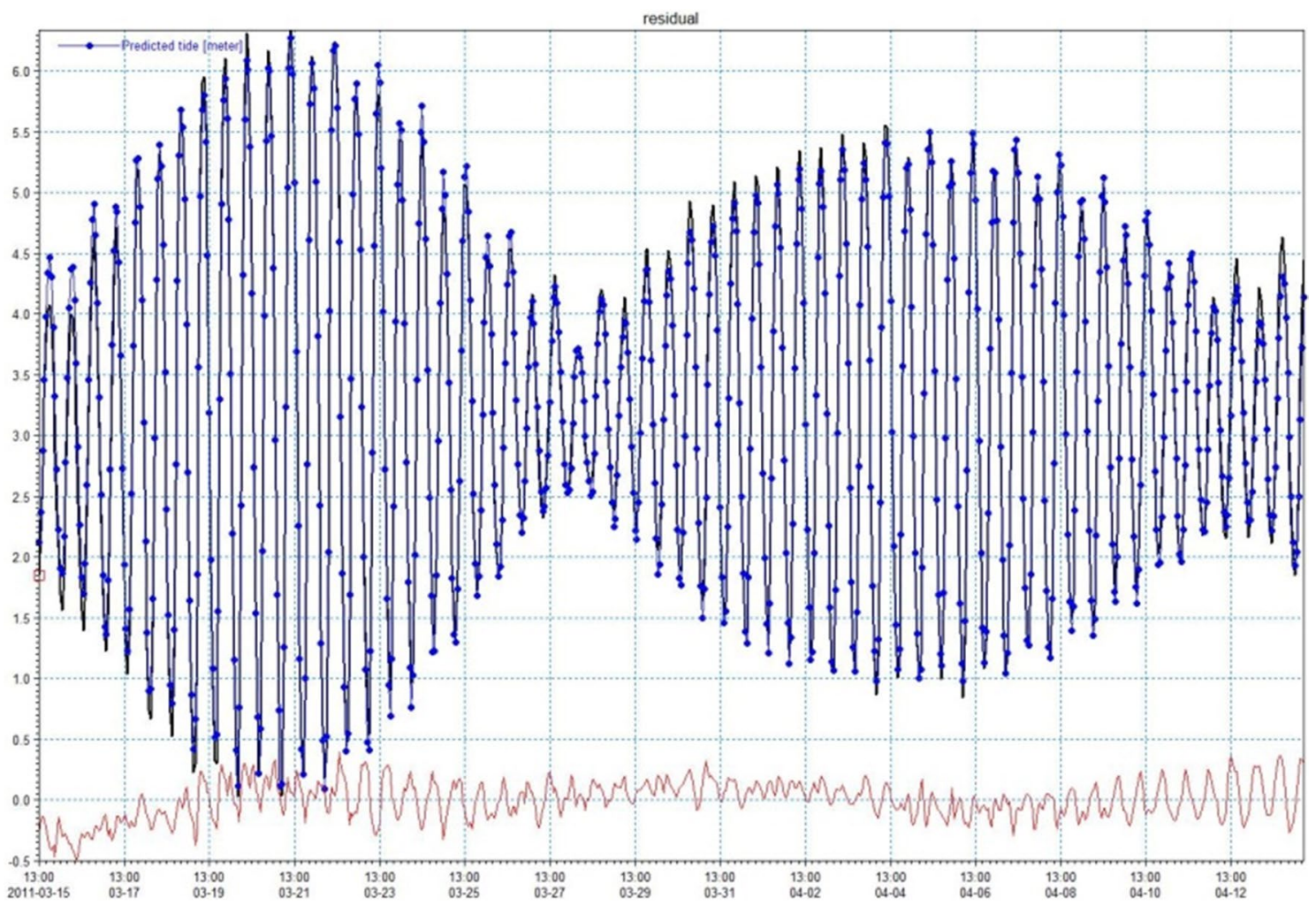

Fig. 8 Observed and predicted tides along with residual tide (in meters) using MIKE21 model

of sediments from the mouth of the Sundarbans ecosystem, having implications on erosion-accretion patterns of the earthen embankment. A total of 30 tidal current constituents were extracted from the analyses, and the study indicates that $\mathrm{M}_{2}, \mathrm{~S}_{2}, \mathrm{~N}_{2}, \mathrm{M}_{4}, \mathrm{MS}_{4}, 2 \mathrm{MS}_{6}$ were found to be the dominant constituents (Fig. 8).

Surface wind speed in the study area has a positive correlation with current speed (Fig. 2), and it varied from 0.1 to $9.5 \mathrm{~m} / \mathrm{s}$ [28]. The results signify that the geographical orientation of Kaikhali location controls the current characteristics, and the overall pattern is northeast to southwest predominant over the study region. It implies that the residual current speed is almost equal in magnitude irrespective of the directions. The residual currents in the Sundarbans ecosystem mainly attribute from the longitudinal baroclinic pressure gradient [29]. It is worthwhile to mention that tides contribute to residual currents in a estuarine environment due to nonlinear interaction and that can lead to differential tidal mixing characteristics. Stacey et al. [29] reported that the residual flow is strongly dependent on the timing of stratification beginning within the tidal cycle and developed a bulk Richardson number to predict the onset of stratification. However, as the Sundarbans is a well-mixed ecosystem, residual flow is not controlled by stratification. During flood tides, this straining is reversed and the water column tends to be well mixed, intensifying currents near the bottom. This asymmetric mixing and velocity profile can lead to a residual flow with the same structure as density-driven circulation creating a seaward flow near the surface and landward flow at the bottom [30]. During ebb tides, the tidal currents can stratify the water column through straining of the density field by the interaction between density gradient and vertically sheared velocity profile. Based on the observational data, it is evident that freshwater from small creeks and channels joining the mainstream river played a major role in accelerating the current speed (Fig. 9).

\section{Conclusion}

The present study reveals that the tidal characteristics at Kaikhali location in the Sundarbans region are semidiurnal in nature. The non-tidal components are important and the overall hydrodynamic flow follows the ebb and flood phases of the tidal cycle. Tidal characteristics in this region are also influenced by the bottom setting of the deltaic environment, meteorological factors, cyclone induced storm surges and freshwater discharge into the shallow estuarine environment. The sea level variation along a coast attributes from various physical factors such as astronomical tides and currents, meteorological forcing and hydrological aspects. The 
Tidal current

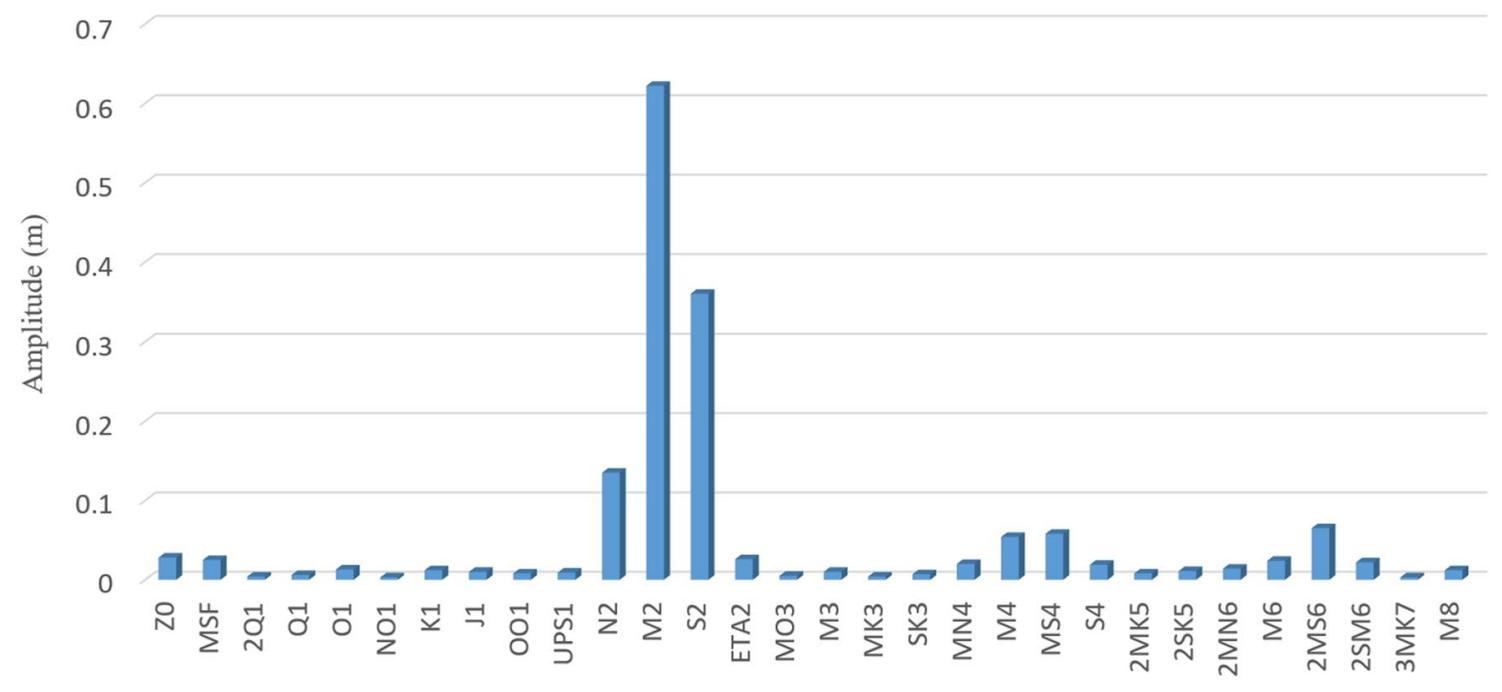

Fig. 9 Amplitude of various tidal constituents (in meters) for the study region

major dominant tidal constituent is the principal lunar $\left(M_{2}\right)$ that contributes about $58 \%$ of the total amplitude and the other components such as $\mathrm{S}_{2}, \mathrm{~K}_{1}, \mathrm{O}_{1}$ and $\mathrm{N}_{2}$ also dominate at the Kaikhali location. Predominant tidal currents are from NE and SW directions in the Sundarbans estuary. The present study demonstrates a comprehensive analysis of tidal characteristics and its prediction for Kaikhali compared against Gangra location in the near vicinity. The study signifies that similar work can be extended to other regions in this estuary in order to understand the role of tidal and non-tidal components in the resultant water level elevations.

Acknowledgements The corresponding author is indebted to the Director, Institute of Environmental Studies and Wetland Management, and Department of Environment, Government of West Bengal, Kolkata, for the support.

Funding This study was funded by Institute of Environmental Studies and Wetland Management (IESWM) and Department of Environment, Government of West Bengal, Kolkata, India.

\section{Compliance with ethical standards}

Conflict of interest The authors declare that they have no conflict of interest.

Ethical standard Authors state that the research was conducted according to ethical standards.

\section{References}

1. Blasco F (1977) Outline of ecology, botany and forestry of the mangals of the Indian subcontinent. In: Chapman VJ (ed)
Ecosystems of the world 1: wet coastal ecosystems. Elsevier, Amsterdam, pp 241-260

2. Goodbred SL, Kuel SA (2000) The significance of large sediment supply, active tectonism, and eustasy on margin sequence development: late Quaternary stratigraphy and evolution of the Ganges-Brahmaputra delta. Sediment Geol 133:227-248

3. Ganguly D, Mukhopadhyay A, Pandey R, Mitra D (2006) Geomorphic study of Sundarbans deltaic estuary. J Indian Soc Remote Sens 34(4):431-435

4. Hansen DV, Rattray M Jr (1965) Gravitational circulation in straits and estuaries. J Mar Res 23:104-122

5. Mao Q, Ping S, Kedong Y, Jianping G, Yiquan Q (2004) Tides and tidal currents in the Pearl River estuary. Cont Shelf Res 24:1797-1808

6. Rose L, Bhaskaran PK, Kani SP (2015) Tidal analysis and prediction for the Gangra location, Hooghly estuary in the Bay of Bengal. Curr Sci 109(4):745-758

7. Boon JD (2010) Secrets of the tide: tide and tidal current analysis and applications, storm surges and sea level trends. Woodhead Publishing, Cambridge, p 2010

8. Mac Cready P (1999) Ecosystem adjustment to changes in river flow and tidal mixing. J Phys Oceanogr 29:708-726

9. Bhattacharyyaa S, Pethick J, Sarma KS (2013) Managerial response to sea level rise in the tidal estuaries of the Indian Sundarbans: a geomorphological approach. Water Policy 15:51-74

10. Misra SK, Chandramohan P, Murty AS, Panigrahi JK, Mahadevan $R$ (2013) Nature of the tide induced flow field along the East Coast of India. Int J Oceans Oceanogr 7(1):57-71

11. Richards JF, Flint EP (1990) Long-term transformations in the Sundarbans wetlands forests of Bengal. Agric Hum Values $7(2): 17-33$

12. Stanley DJ, Hait AK (2000) Holocene depositional patterns, neotectonics and Sundarban mangroves in the western GangesBrahmaputra delta. J Coast Res 16(1):26-39

13. Nicholls RJ, Marinova N, Lowe J, Brown S, Vellinga P, de Gusmão D, Hinkel J, Tol R (2011) Sea level rise and its possible impacts given a 'beyond $4{ }^{\circ} \mathrm{C}$ world' in the twenty-first century. Philos Trans R Soc Lond Ser A 369:1-21 
14. Pethick J, Orford JD (2013) Rapid rise in effective sea-level in southwest Bangladesh: its causes and contemporary rates. Glob Planet Change 111:237-245

15. Goutam KS, Tanaya D, Anwesha S, Sharanya C, Meenakshi $C$ (2015) Tide and mixing characteristics in Sundarbans ecosystem river system. Hydrol Curr Res 6:204. https://doi. org/10.4172/2157-7587.1000204

16. Lumbroso D (2007) Review report of operational flood management methods and models (No. T17-07-01). HR Wallingford \&WL Delft Hydraulics, Wallingford, UK, p 60

17. Moftakhari HR, AghaKouchak A, Sanders BF, Allaire M, Matthew RA (2018) What is nuisance flooding? Defining and monitoring an emerging challenge. Water Resour Res 54:4218-4227. https ://doi.org/10.1029/2018WR022828

18. Woodroffe CD, Nicholls RJ, Saito Y, Chen Z, Goodbred SL (2006) Landscape variability and the response of Asian mega deltas to environmental change. In: Harvey N (ed) Global change and integrated coastal management, vol 10. Springer, Dordrecht, pp 277-314. https://doi.org/10.1007/1-4020-3628-0

19. Henry RF, Murty TS (1989) Requirements for tidal measurement in the Bay of Bengal and Arabian Sea. Mar Geod 13(3):179-182. https://doi.org/10.1080/15210608909379621

20. Unnikrishnan AS, Luick JL (2003) A finite element simulation of tidal circulation in the Gulf of Kutch, India. Estuar Coast Shelf Sci 56(1):131-138

21. Rose Linta, Bhaskaran Prasad K (2017) Tidal propagation and its non-linear characteristics in the head Bay of Bengal. Estuar Coast Shelf Sci 188:181-198. https://doi.org/10.1016/j. ecss.2017.02.024

22. Chatterjee M, Shankar D, Sen GK, Sanyal P, Sundar D, Michael GS, Sarkar K (2013) Tidal variations in the Sundarbans estuarine system. J Earth Syst Sci 122:899-933. https://doi.org/10.1007/ s12040-013-0314-y

23. Warren IR, Bach HK (1992) MIKE 21: a modelling system for estuaries, coastal waters and seas. Environ Softw 7(4):229-240

24. Milliman JD, Broadus DJM, Gable F (1989) Environmental and economic implications of rising sea level and subsiding deltas: the Nile and Bengal examples. Ambio 18(6):340-345

25. Hazra S, Ghosh T, DasGupta R, Sen G (2002) Sea level and associated changes in the Sundarbans. Sci Cult 68(9-12):309-321 (ISSN 0036-8156)

26. https://www.revolvy.com/page/Tidal-range

27. Smith JD, Long CE (1976) The effect of turning in the bottom boundary layer on continental shelf sediment transport. Mem Soc R Sci Liege 6(X):369-396

28. Selvin Pitchaikani J, Kakoli SS, Somenath Bhattacharyya (2017) First time report on the weather patterns over the Sundarban mangrove forest, East Coast of India. Indian J Geo Mar Sci 46(04):766-770

29. Stacey MT, Burau JR, Monismith SG (2001) Creation of residual flows in a partially stratified estuary. J Geophys Res 106:17013-17037

30. Stacey MT, Fram JP, Chow FK (2008) Role of tidally periodic density stratification in the creation of ecosystem subtidal circulation. J Geophys Res 113:C08016. https://doi.org/10.1029/2007J C004581

Publisher's Note Springer Nature remains neutral with regard to jurisdictional claims in published maps and institutional affiliations. 